\title{
EFFECT OF PLATE SURFACE CONDITIONS ON ACCELERATED COOLING PERFORMANCE
}

\author{
Emanuelle Garcia Reis ' \\ Antonio Augusto Gorni ' \\ Daniel Bojikian Matsubara' \\ Edmar de Souza Silva ${ }^{2}$ \\ lan Robinson ${ }^{3}$ \\ José Herbert Dolabela da Silveira ' \\ Rafael Abreu Fraga' \\ Rodney Pardo Alves '
}

\begin{abstract}
The purpose of the accelerated cooling process during plate production is to increase the mechanical strength of the final plate, together with improved toughness and weldability, in lower carbon equivalent steels. This process is affected by the quality of the plate surface during cooling, the plate shape after rolling and the conditions of the cooling process itself. These conditions need to be carefully controlled and are mostly influenced by the scale formation and the temperatures uniformity of the product; from the slab reheating to the end of the accelerated cooling. The surface descaling must be performed in an integrated manner that achieves a homogeneous temperature profile after accelerated cooling, over the entire plate in three dimensions: thickness, width and length.
\end{abstract}

Keywords: Plate mill, Flatness, Accelerated cooling, Controlled rolling, Scale.

\section{EFEITO DAS CONDIÇÕES SUPERFICIAS DA CHAPA NO DESEMPENHO DO RESFRIAMENTO ACELERADO}

\section{Resumo}

O objetivo do processo de resfriamento acelerado na laminação de chapas grossas é promover o aumento da resistência mecânica do produto acabado, concomitantemente com a melhoria da tenacidade e da soldabilidade, em aços com menor carbono equivalente. Este processo tem a maior eficácia dependendo da qualidade da superfície da chapa que está sendo resfriada, da forma do esboço após a laminação e das condições do próprio processo de resfriamento. Para isto, as condições da formação da carepa, a uniformidade das temperaturas de processo, desde o aquecimento das placas até o final do resfriamento acelerado, as condições de descamação superficial devem ter todo o seu controle de processo executado de uma maneira integrada, que permita a uniformidade do resfriamento ao longo de todo o esboço, nas três dimensões: espessura, largura e comprimento.

Palavras-chave: Laminação de chapas grossas; Planicidade; Resfriamento acelerado; Laminação controlada; Carepa.

\section{INTRODUCTION}

In order to obtain the target mechanical properties in the accelerated cooling process after controlled rolling, a process known as Thermo-Mechanically Controlled Processing (TMCP), it is very important to control the surface quality of the rolled plate. The first condition for having a homogeneous accelerated cooling process is for superficial scale to be uniform so as not to prejudice the uniformity of plate temperature throughout the rolling process, from slab reheating until the forced water cooling. Non-uniformity of the scale thickness directly affects the final shape and mechanical properties of the plate. It is essential that in all stages of the production process that there is a uniform

'Gerência de Laminação de Chapas Grossas, Gerdau Ouro Branco, Ouro Branco, MG, Brasil. E-mail: herbertsilveira@yahoo.com.br ${ }^{2}$ Centro de Testes, Gerdau Ouro Branco, Ouro Branco, MG, Brasil.

3Primetals Technologies, Sheffield, UK.

2176-I523 (C) 2020. Reis et al. Published by ABM. This is an Open Access article distributed under the terms of the Creative Commons Attribution License, which permits unrestricted use, distribution, and reproduction in any medium, provided the original work is properly cited. 
temperature evolution, starting with the slab reheating a controlled decrease of the temperature of the plate in the rolling and cooling stages should be achieved.

Obtaining a homogeneous surface heat transfer condition can occur without the interference of an insulating scale layer which is non-uniform in its formation or removal from the plate surface. The scale formation, to be suitable during the reheating process, requires that there is good control in the process parameters of the reheating furnace. The main control parameters during the reheating process are the total heating time of the slabs, the temperatures of each zone and the internal atmosphere in the reheating furnace. The basic rule for this process is not to allow excessive heating time, which is achieved by obeying the best reheating curve, based on mathematical models that allow the best thermal soaking in all slab dimensions. Another parameter to be controlled is the maintenance of the air / fuel ratio, which must be as stable as possible for the fuel used, passing from a slightly reducing initial atmosphere in the first zones to a somewhat oxidizing atmosphere in the final zones of the reheating furnace; not allowing oxygen excess inside of the furnace.

Thereafter, following the discharging and primary descaling, it is necessary to ensure high efficiency in the scale removal that forms on the plate from the furnace exit until the beginning of the accelerated cooling.

Another important parameter that must be controlled very efficiently is the descaling process that occurs in controlled rolling, the descaling should be strictly controlled and consistent through the pass schedule, design and maintenance of the right descaling nozzles, adjusting the best relative positions of height and attack angle of each descale header, and correctly positioning the respective nozzles. State of the art nozzles have high impact force values, which aid in the secondary and tertiary scale removal in the rolling.
In the Gerdau Ouro Branco's Plate Mill there are process controls that use mathematical models of the reheating furnace to optimize the slab heating. The aim is to reduce excessive formation of the primary scale and reduce adherence to the slab surface which will make it more difficult to remove in the descaling steps. The Ouro Branco plate mill has the most modern descaling system, with strategically placed high pressure and high impact nozzles. There is also an automatic descaling strategy during the pass schedule, but it can be actuated manually by the operator, if necessary. After the mill there are a pre-leveler and an accelerated cooling machine called MULPIC (multi propose interrupted cooling) [I].

This paper will show the performance results and controls that are performed during TMCP.

\section{INFLUENCE OF SCALE ON HEAT TRANSFER}

The surface scale layer that forms during the rolling process is thermally insulating, which causes different cooling conditions throughout the plate as a function of the heat transfer phenomena that occur during each step of the hot rolling process. The influence of scale thickness, shape and its adhesion to the plate surface were analyzed in several studies [2-5]. It has shown that the scale and its physical characteristics results in different values of heat transfer coefficient in the plate during the accelerated cooling process.

Different coefficients and heat fluxes that are produced in the presence of the scale [2]. Scale thickness will add a thermal insulating layer which prevents heat loss and reduces the heat transfer coefficient during air cooling [3]. Figures I, 2, 3 and 4 show experimentally that the thickness and the roughness of the scale influence the cooling rates and the surface temperatures achieved by the plate [2].
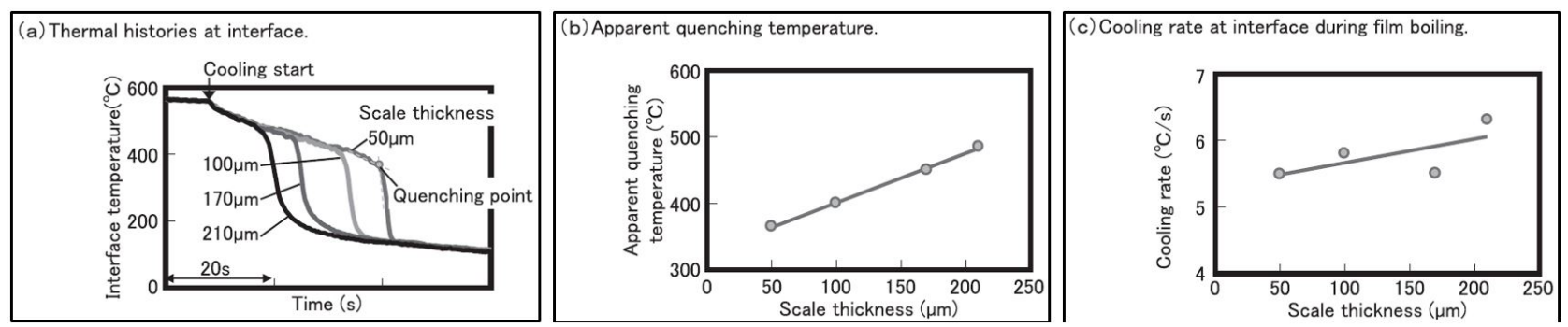

Figure I. Effects of scale thickness on spray cooling characteristics (scale type Al2O3, water flow density $0.00167 \mathrm{~m}^{3} / \mathrm{m}^{2} \mathrm{~s}$ ) [2].
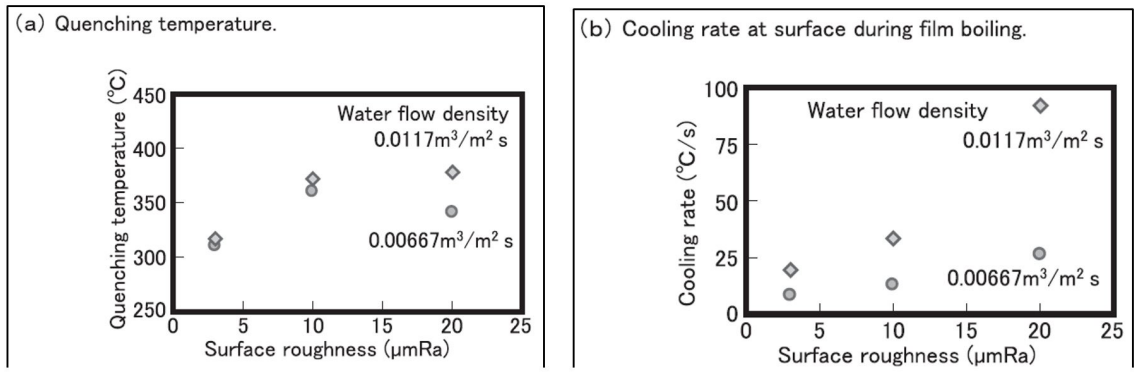

Figure 2. Effects of surface roughness on spray cooling characteristics (Non-coating) [2]. 

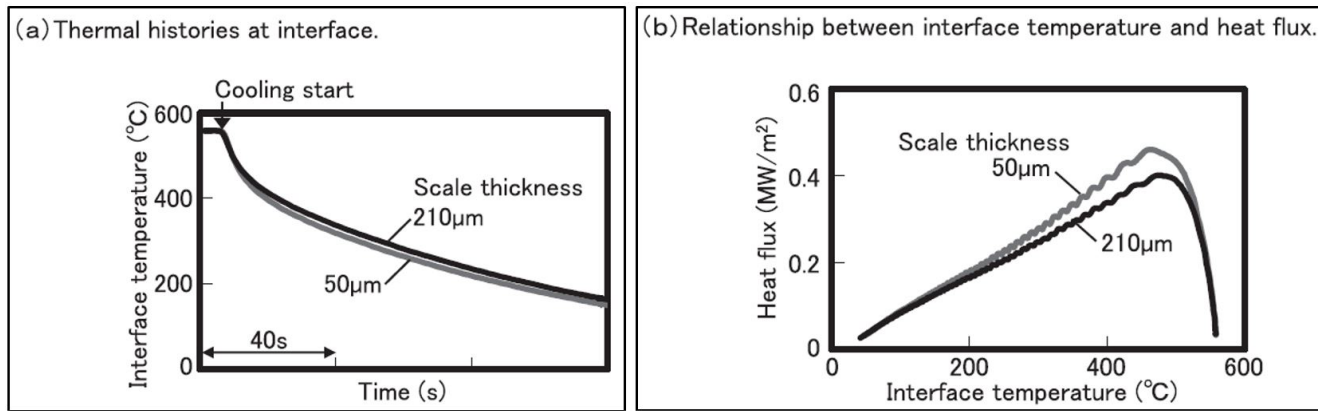

Figure 3. Effect of scale thickness on air jet cooling (scale type Al2O3, Air flow density $3.83 \mathrm{~N} \mathrm{~m}^{3} / \mathrm{m}^{2} \mathrm{~s}$ ) [2].
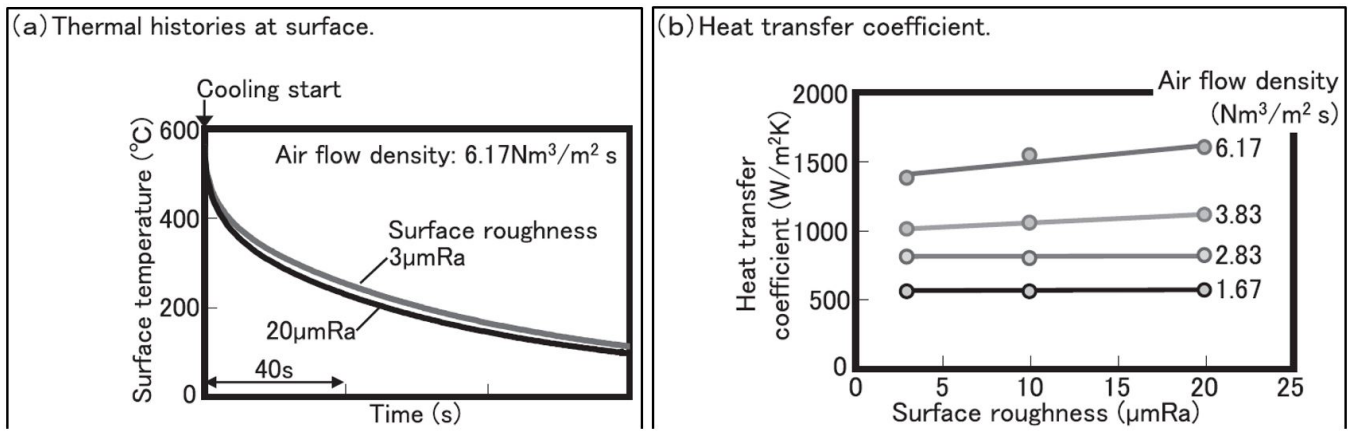

Figure 4. Effect of surface roughness on air jet cooling (Non-coating) [2].

Greater scale thicknesses promote strong variations in the corresponding heat transfer coefficients along a broad surface temperature range. As can be seen in Figure 5, this demonstrates how the scale thickness changes the heat transfer coefficient and therefore the surface temperature of the plate during spray cooling [3]. Mother plates showing different surface scale thicknesses can have different local cooling rates which can lead to temperature heterogeneity.

The cooling capacity of water during the accelerated cooling of a steel plate at high temperature shows a characteristic behavior defined by the boiling curve, Figure 6 . Serizawa et al. [6] explained that "in the high temperature region, a stable steam vapor film is formed between the steel plate and the water, causing a state termed as film boiling and, despite a high temperature in the region, the cooling capacity becomes slightly lower".

Kim et al. [7] showed that when a liquid droplet is placed on a surface held at a temperature much higher than the liquid's boiling point, it hovers on a vapor cushion without wetting the surface. This phenomenon is called film boiling and occurs at surface temperatures beyond the "Leidenfrost point (LFP)." If the surface temperature is at or above the LFP, heat transfer from the surface to the liquid takes place by conduction and radiation through the vapor layer, and thus the liquid takes a significantly longer time to evaporate than it would on a surface held at lower temperature.

Serizawa et al. [6] explained that

as the steel plate temperature goes down, contacting of water with the steel plate starts and, as the steel plate temperature further goes down, the area of

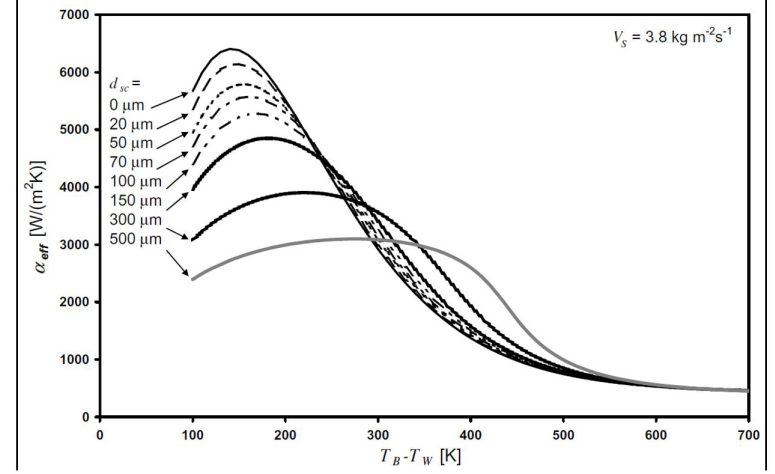

Figure 5. Effective HTC $\alpha$ eff for different values of scale layer thickness and $\mathrm{Vs}=3.8 \mathrm{~kg} /\left(\mathrm{m}^{2} . \mathrm{s}\right)[3]$.

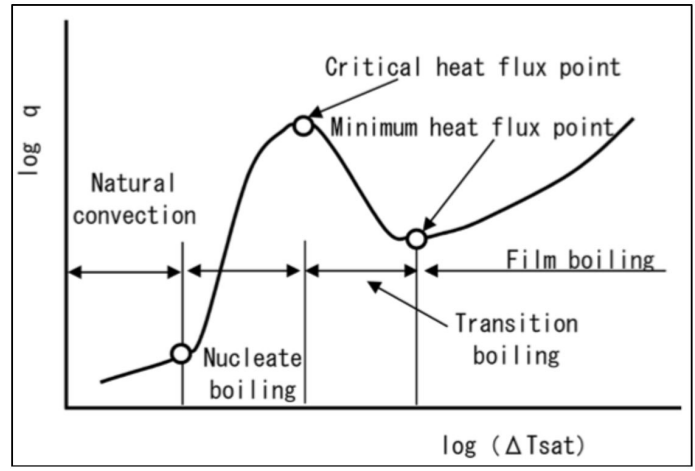

Figure 6. Boiling curve of water [6].

contact of water with the steel plate expands and the state of cooling enters the transition boiling region where the cooling capacity increases. As the temperature of the plate further goes down, the 
state of cooling goes into the nucleate boiling region where bubbles generated play a major role. In cooling steel plates, cooling in the transition boiling region is crucial. In this region, as the cooling capacity increases along with the decrease in plate temperature, uneven temperature distribution within a steel plate developed in the earlier cooling is enlarged and, finish cooling temperature also varies for each steel plate.

Figure 7 shows how scale can interfere with the steam layer during cooling. Scale can shift the Leidenfrost temperature from film boiling to transition boiling and interrupt and break up the film boiling steam layer and help to initiate the movement to transition boiling [7].

Lee [4] stated that the surface roughness of the plate, which is influenced by the scale formation, changes the phenomenon of heat transfer in the accelerated cooling process of the plate. Generally, the rougher the surface, the higher the Leidenfrost temperature. A rough surface also increases the surface contact area with the water under the cooling nozzle and rough scale will increase the nucleation site for steam bubbles to form for nucleate boiling [5].

The effect of the roughness on the cooling efficiency was proven experimentally by Prodanovic et al. [5], where increased roughness led to an increase in plate cooling time between $700^{\circ} \mathrm{C}$ and $100^{\circ} \mathrm{C}$, as shown in Figure 8. In this example roughness is quite small, and it could be that the Leidenfrost temperature increases but the peak heat flux reduces as in Figure 5.

As it is shown the scale/water and heat transfer are clearly a complex phenomenon.

Flatness is influenced by austenite transformation which is also related to temperature, as it is not instantaneous, and the final phases have different specific weights than the original austenite. This is one of the causes of residual stress in the plate, and the resulting strain depends on the formed constituents: pearlite/ferrite mixture, bainite and martensite $[8,9]$. Figures 9 and $10[9]$ show the volume change and the consequences of tensile stresses.

Figure II [10] show at a cooling finishing cooling temperature target of $670^{\circ} \mathrm{C}$ the temperature is close to the point where the phase change finishes and there is a change in the coefficient of thermal expansion at this point. A higher plate temperature will cause a shorter length. Figure 12 [II] shows another example of the increase in length with transformation from austenite to martensite. It will affect directly the final plate flatness and internal stress.

The emissivity of the scale influences the temperature measured by the pyrometer which has a single emissivity set for a clean scale free steel surface so the apparent surface temperature can be different from the actual.

The objective of this study was to evaluate the influence of surface scale formed during the rolling process on the performance of the accelerated cooling process.

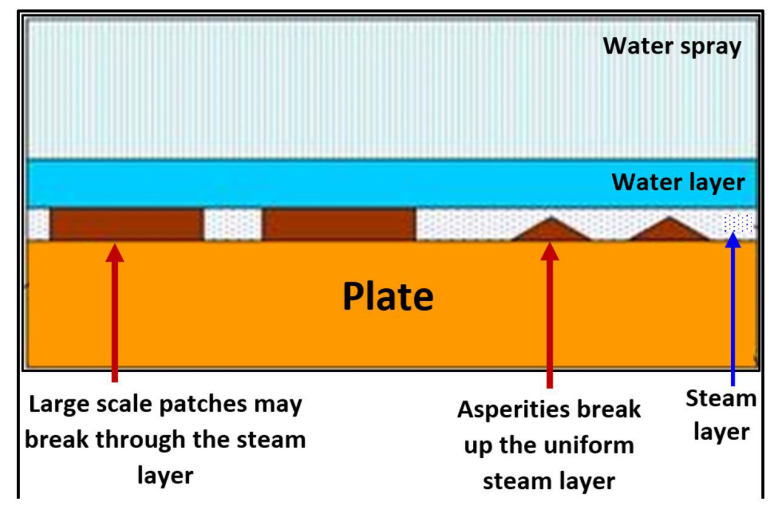

Figure 7. Scaled or uneven plate surface.

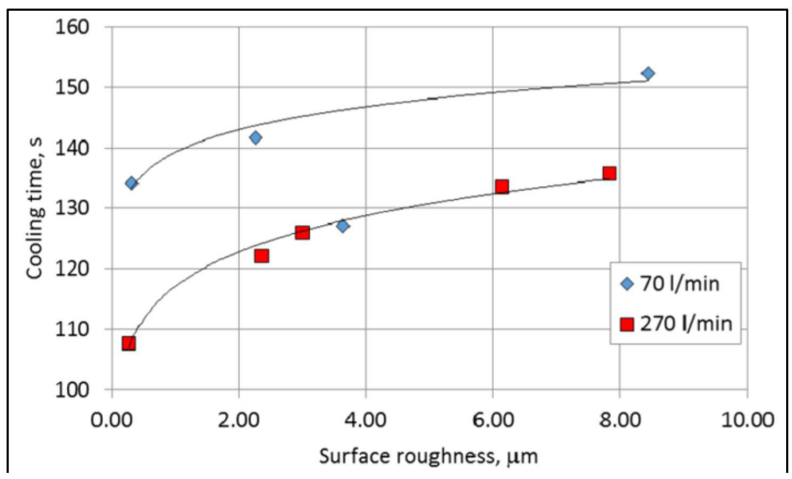

Figure 8. The effect of surface roughness on the time to cool the plate from $700^{\circ} \mathrm{C}$ to $100^{\circ} \mathrm{C}$ for parallel flow cooling with two different flow rates [5].

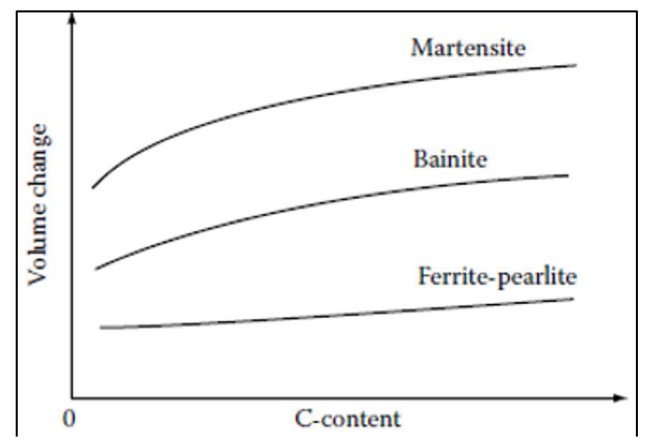

Figure 9. Volume changes vs. carbon contents of plain carbon steel due to martensitic, bainitic, and ferrite-pearlitic transformation (schematically) [9].

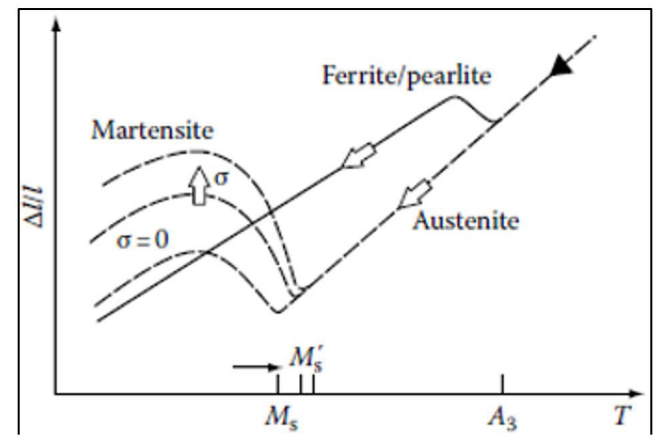

Figure 10. Consequences of tensile stresses on the relative changes of length during rapid cooling of austenitized steel specimens compared with slow cooling behavior [9]. 


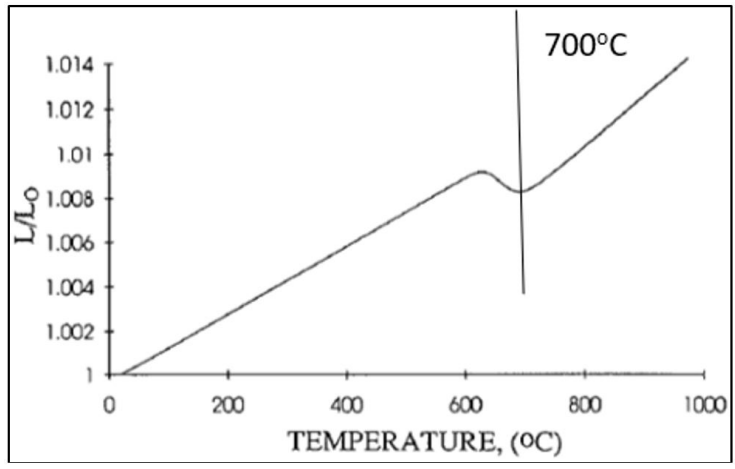

Figure I I. Computed dilatation curve for an AISI IOIO steel. LO is the original length and $L$ is the current length [ 10$]$.

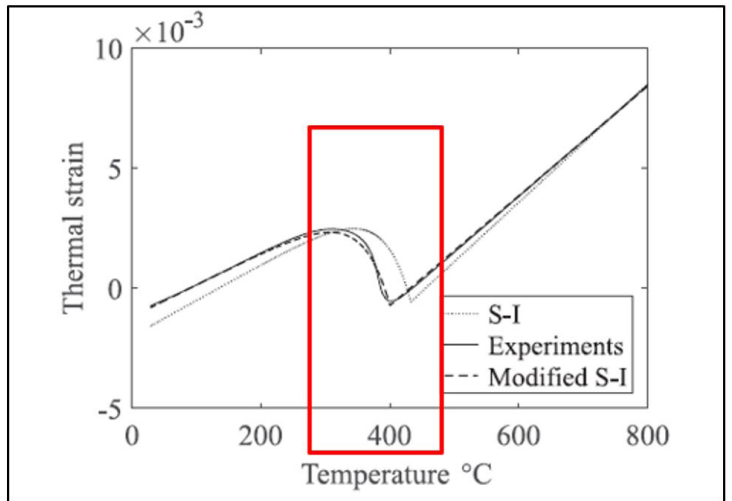

Figure 12. Models and experimental curves of phase transformation from austenite to martensite in Hardox 450, a low alloyed carbon steel [II].

\section{MATERIAL AND METHODS}

Several plates were rolled in the Gerdau Ouro Branco Plate Mill Line. Secondary descaling strategies were changed during the finishing rolling phase. The slab dimension rolled is $250 \times \mathrm{I}, 600$ (thickness $\times$ width) and the mother plate dimension is $25.58 \times 2,550 \times 17,500$ (thickness $\times$ width $\times$ length).

No etching was used to reveal the scale. It was made using a Leica MZ75 stereomicroscope and a Clemex IA 32 image capture program, with a magnitude of $10 \mathrm{x}$. Acetone with ultrasonic cleaning was used in the preparation of the SEM samples. The SEM microscope used here was a model Quanta 400 from FEl; a magnitude of I,500 times was used.

Figure I 3 shows the surface temperature distribution after the accelerated cooling performed under different descaling strategies. The dark regions have lower temperatures, which may be as a result of different surface conditions such as scale.

Figure 14 shows the region of a plate where non-uniform descaling occurred due to the absence of a descaling nozzle. Samples were taken from this location for metallographic and mechanical analysis.

Figure 15 shows the visual appearance of the upper face of one of these samples, showing the interface between fine (at left) and coarse (at right) scale. It can be observed that the roughness of the surfaces between the two scales morphologies are different.

Figure $16 a$ and $b$ shows the cross sections of thin and coarse scale, including their thicknesses at several points.

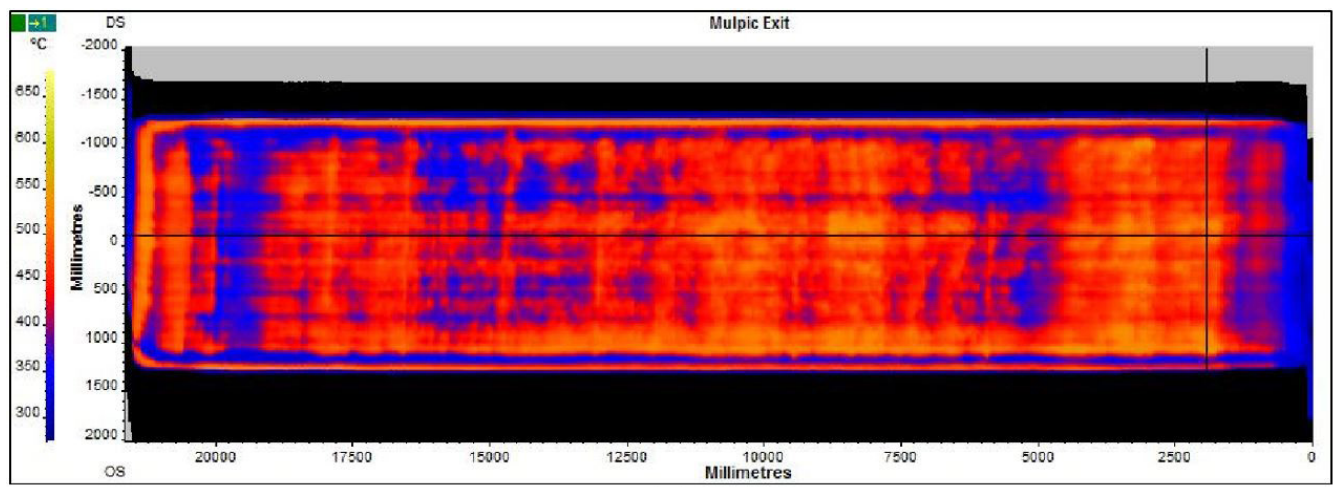

(a)

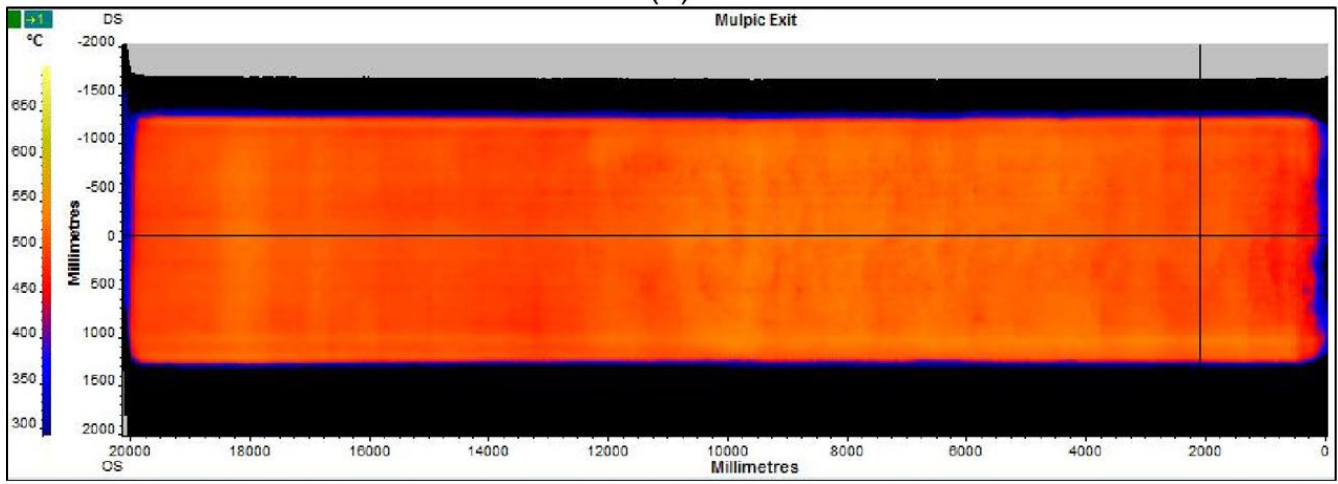

(b)

Figure 13. Thermographic image of the mother plate after accelerated cooling, with (a) heterogeneous scale and (b) homogeneous scale. 


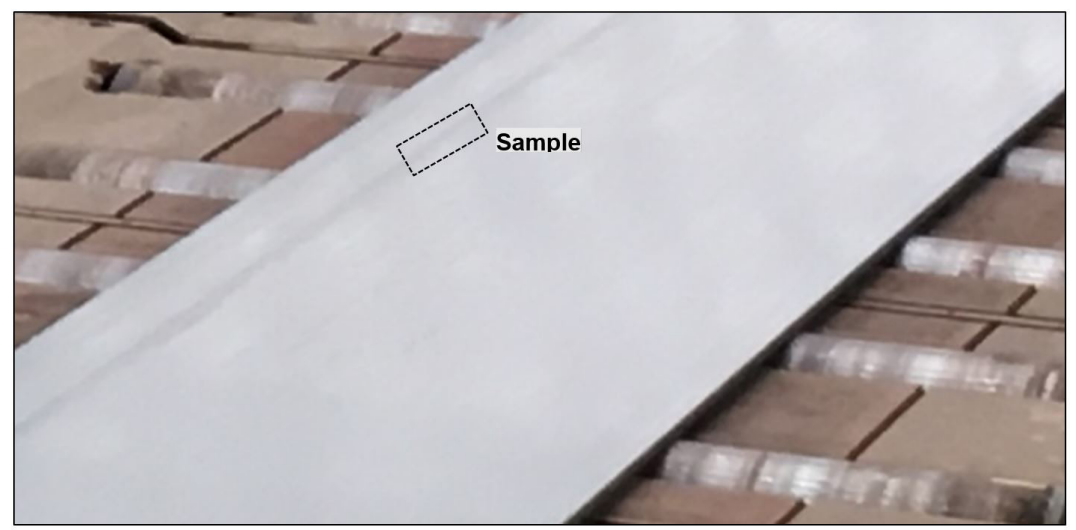

Figure 14. Plate with not uniform descaling.

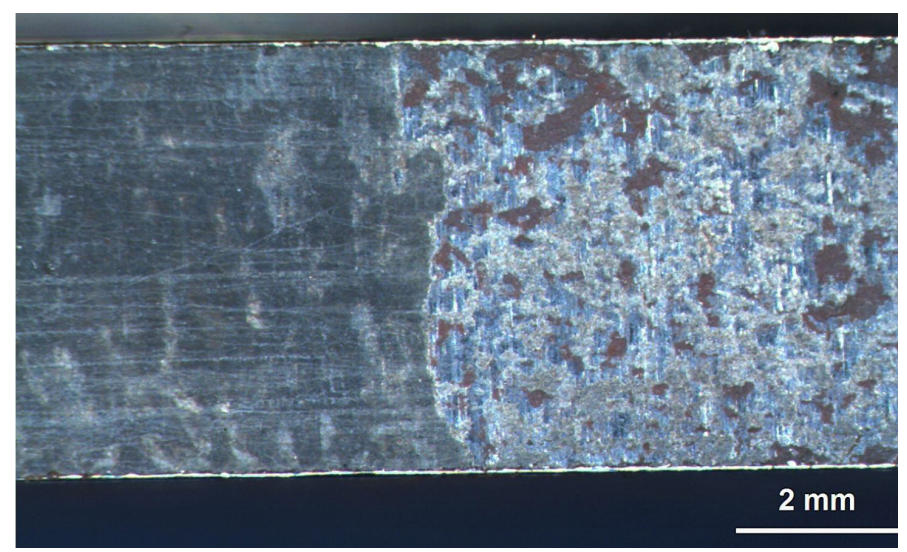

Figure 15. Visual appearance of the upper face of the fine scale and the coarse scale.

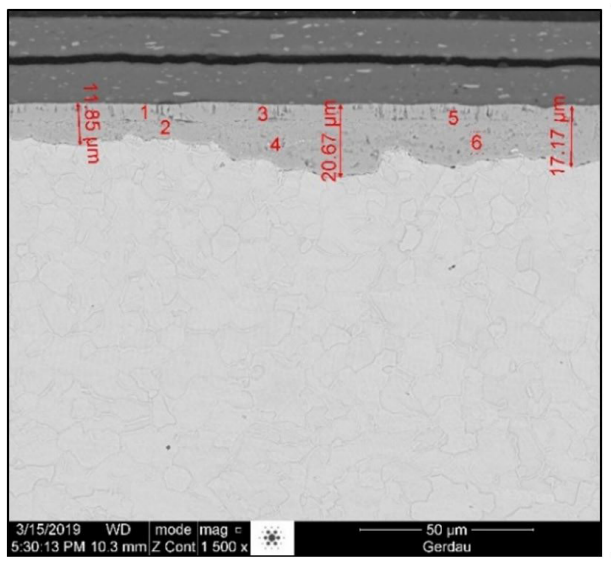

(a)

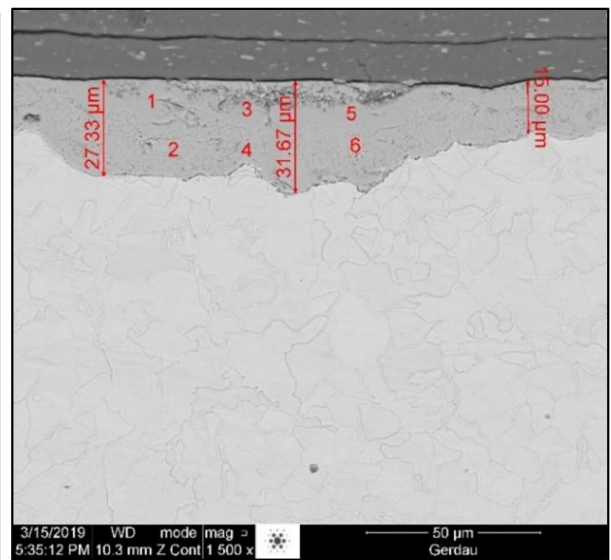

(b)

Figure 16. Image obtained by scanning electron microscopy (SEM) of the cross section in the samples with (a) thin scale, e (b) coarse scale.

Table I shows the results from the tensile tests obtained from samples extracted in the regions with fine and coarse scale. It is possible to observe that the sample with coarse scale obtained higher values of yield and tensile strength, as well as elongation.

Figure 17 shows an example of the finishing accelerated cooling temperature variation and the corresponding tensile strength values along the centerline length of a mother plate. It is observed that the tensile strength is inversely proportional to this temperature and that the variation of this last parameter probably comes from the scale non-uniformity. The tensile strength values range is from $690 \mathrm{MPa}$ to $849 \mathrm{MPa}$, excluding head and tail values of the mother plate.

Figure $18 a, b, c$, and $d$ shows the final shape of a rolled plate with the scale on its tail. The plate showed flatness defects in the tail after exiting the accelerated cooling machine. The plate showed good flatness at the hot leveler exit but, as it remained in the cooling bed, the flatness defect reappeared. 
Reis et al.
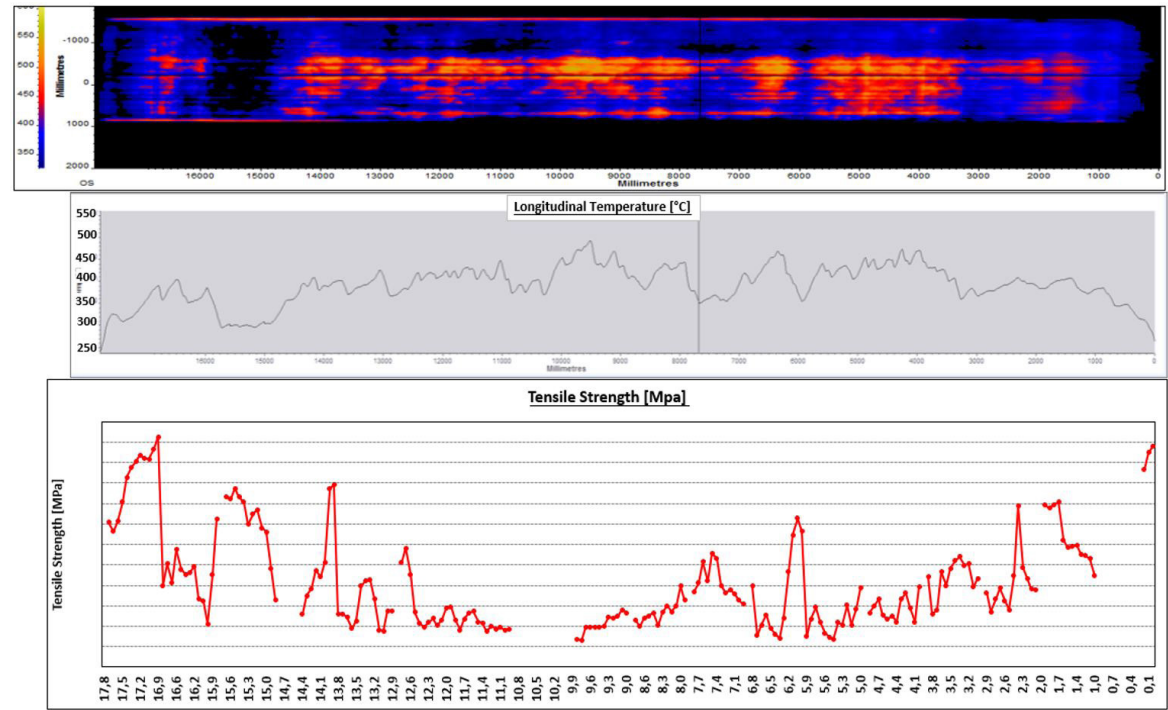

Figure 17. Variation of the tensile strength as a function of the final cooling temperature in a plate with heterogeneous scale distribution.

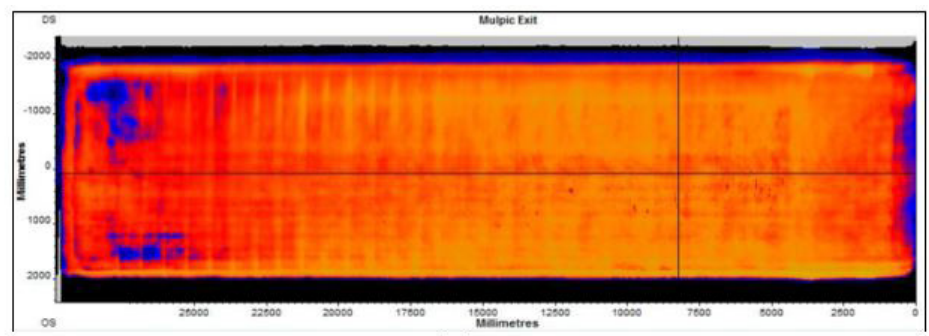

(a)

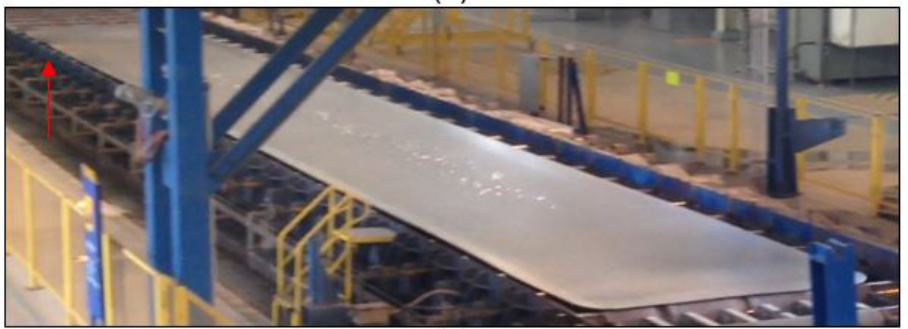

(b)

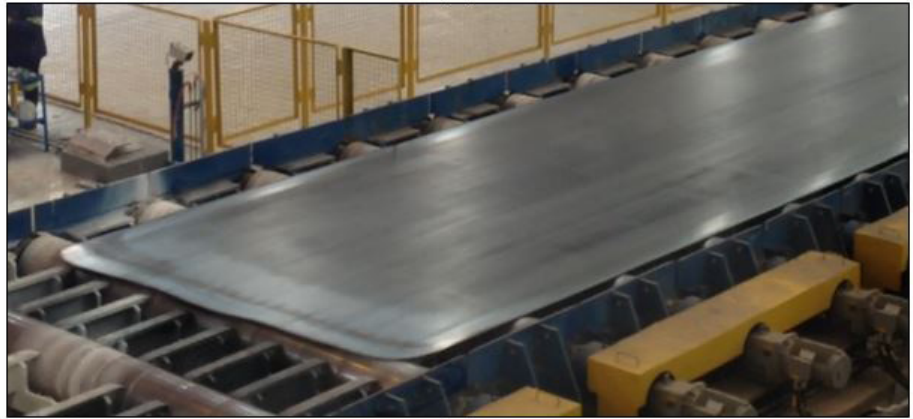

(c)

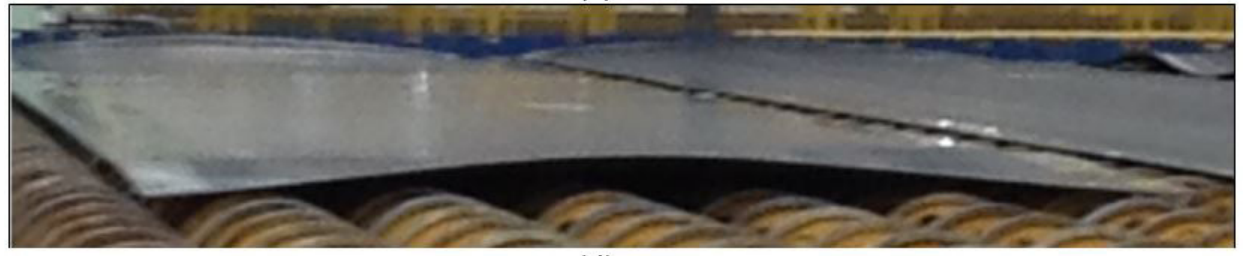

(d)

Figure 18. (a) Thermographic image of a mother plate that showed scale located at the tail, (b) the same plate after accelerated cooling with flatness defect at the tail, (c) showing good flatness at the tail after hot leveler, and (d) showing flatness defect after air cooling. 
Table I. Tensile test result in the sample with fine and thick scale

\begin{tabular}{lccc}
\hline \multicolumn{1}{c}{ Sample } & $\begin{array}{c}\text { Yield Stress } \\
\mathbf{0 . 5 \%} \\
{[\mathrm{MPa}]}\end{array}$ & $\begin{array}{c}\text { Tensile } \\
\text { Strength } \\
{[\mathrm{MPa}]}\end{array}$ & Elongation \\
\hline Fine Scale & 414 & 487 & 58 \\
Coarse Scale & 427 & 527 & 62 \\
\hline
\end{tabular}

\section{RESULTS}

The values of mechanical strength were higher in the regions with lower finishing cooling temperature and coarse scale, due to the higher values of heat transfer in these regions. As can be seen from Table I.

The presence of the non-uniform scale on the mother plate surface causes local variations in the values of heat transfer coefficient and heat flows. The regions with thicker scale have higher Leidenfrost temperature. The consequent expansion of the transition boiling range increased the average heat transfer coefficient, thereby increasing the cooling rate and reducing the final temperature of accelerated cooling where scale was thicker [2,3].

The plate thermography after accelerated cooling can be seen in Figure I 3 and the presence of thicker scale shows lower temperatures. Different roughness levels are visually perceived in the regions with coarse scale compared to the rest of the plate.
These flatness problems were correlated with the formation of heterogeneous scale. The different temperature gradients generate different residual stress states that remain present in the mother plate after the hot levelling process.

The scale morphology influences the final cooling temperature, final flatness and mechanical properties.

\section{CONCLUSIONS}

The homogeneity and effectiveness of obtaining the desired mechanical properties of the plate after the accelerated cooling process combined with controlled rolling (the TMCP process) is strongly dependent on the plate surface quality during these processes coupled with the shape and flatness of the plate before cooling. The scale formed from the reheating process and during rolling has a significant effect on the plate final performance, as thicker scale increases the local heat transfer coefficient during accelerated cooling and leading to higher strength.

The efficiency of the accelerated cooling is strongly correlated to the different heat transfer coefficients locally prevailing on the mother plate surface as a result of the variations in thickness and roughness of the scale that occur throughout the thermomechanical treatment.

\section{REFERENCES}

I Robinson I, Kilato J, Hinton J. A recent application of the mulpic ${ }^{\circledR}$ Advanced cooling technology to improve high strength plate steel production. In: Proceedings of the the Iron and Steel Conference and Exposition - AISTech; 20I9; Pittsburgh. Pittsburgh: Association for Iron and Steel Technology; 2019. 8 p.

2 Fukuda H, Nakata N, Kijima H, Kuroki T, Fujibayashi A, Takata Y, et al. Effects of surface conditions on spray cooling characteristic. ISIJ International. 2016;56:628-636.

3 Wendelstorf R, Spitzer K, Wendelstorf J. Effect of oxide layers on spray water cooling heat transfer at high surface temperatures. International Journal of Heat and Mass Transfer. 2008;5I:4892-490.

4 Lee J. Role of surface roughness in water spray cooling heat transfer of hot steel plate. ISIJ International. 2009;49:1920-I925.

5 Prodanovic V, Militzer M, Kirsch H, Schorr R, Schwinn V. The effect of surface roughness on accelerated cooling. In: Proceedings of the 5th International Conference on Thermomechanical Processing - TMP; 2016 Oct; Milan. Milan: Associazione Italiana di Metalurgia. $8 \mathrm{p}$.

6 Serizawa Y, Nakagawa S, Kadoya Y, Yamamoto R, Ueno H, Haraguchi Y, et al. Plate cooling Technology for the Thermo Mechanical Control Process (TMCP) in nippon steel \& sumitomo metal corporation. Nippon Steel \& Sumitomo Metal Technical Report. 2015; I 10:17-24.

$7 \mathrm{Kim} \mathrm{H}$, Truong B, Buongiorno J, Hu L. On the effect of surface roughness height, wettability, and nanoporosity on leidenfrost phenomena. Applied Physics Letters. 201 I;98:083 121 .

8 Qiu Z, He A, Shao J, Xia X. Reduction of residual stress for high-strength low-alloy steel strip based on finite element analysis. Advances in Materials Science and Engineering. 2018;2018:8131909.

9 Schulze V, Vöhringer O, Macherauch E. Residual stresses after quenching. In: Liscic B, Tensi HM, Canale LCF, Totten GE, editors. Quenching theory and technology. 2nd ed. Boca Ratón: CRC Press; 2010. p. 229-288.

I0 Boyadjiev I, Thomson P, Lam Y. Computation of the diffusional transformation of continuously cooled austenite for predicting the coefficient Qf thermal expansion in the numerical analysis of thermal stress. ISIJ International. 1996;36:14I3-I4I9.

I I Back J. Modelling and characterisation of the martensite formation in low alloyed carbon steels [thesis]. Luleå, Suécia: Lulea University of Technology; 2017.

Received: 19 Feb. 2020

Accepted: II May 2020

Tecnol. Metal. Mater. Miner., São Paulo, v. I7, n. 2, p. I78-I85, abr./jun. 2020 